\title{
An LC-IT-MS/MS-Based Method to Determine Trichothecenes in Grain Products
}

\author{
Marcin Bryła • Renata Jędrzejczak • Krystyna Szymczyk • \\ Marek Roszko • Mieczysław W. Obiedziński
}

Received: 22 May 2013 / Accepted: 30 August 2013/Published online: 17 September 2013

(C) The Author(s) 2013. This article is published with open access at Springerlink.com

\begin{abstract}
The aim of this work was to evaluate the usefulness of the ion trap mass spectrometry coupled to high-performance liquid chromatography for simultaneous determination of selected trichothecenes (nivalenol, deoxynivalenol, fusarenon-X, neosolaniol, 3-acetyl-deoxynivalenol, diacetoxyscirpenol, HT2 and T-2 toxins) in grain products. These compounds were extracted from the grain products and then cleaned up with the developed, simple and robust procedure using some mixture of neutral alumina, charcoal and diatomaceous earth. Method recovery was $88-125 \%$ depending on combination of the analysed mycotoxins, sample matrix and the fortification level. Method precision expressed by relative standard deviation ranged from 2.6 to $27.4 \%$. The concentrations of the selected trichothecenes have been determined in 94 samples of cerealbased products. Maize-based next to wheat-based products were the most contaminated with deoxynivalenol, neosolaniol, 3-acetyl-deoxynivalenol, diacetoxyscirpenol and HT-2 toxin. In $83 \%$ of wheat-based products, deoxynivalenol was determined at the average level of $249 \mu \mathrm{g} \mathrm{kg}^{-1}$. The highest concentration of deoxynivalenol-2,026 $\mu \mathrm{g} \mathrm{kg}^{-1}$ $\left(476 \pm 471 \mu \mathrm{g} \mathrm{kg}^{-1}\right.$ on the average) - was found in the maize-based product. Other mycotoxins were found much less frequently: 3-acetyl-deoxynivalenol in only one sample at the concentration of $59 \mu \mathrm{g} \mathrm{kg}^{-1}$, neosolaniol, HT-2 toxin and diacetoxyscirpenol in a few samples on average concentrations close to respective limits of quantification.
\end{abstract}

\footnotetext{
M. Bryła $\cdot$ R. Jędrzejczak $\cdot$ K. Szymczyk $\cdot$ M. Roszko Department of Food Analysis, Institute of Agricultural and Food Biotechnology, Rakowiecka 36, 02-532 Warsaw, Poland

M. Bryła $(\bowtie) \cdot$ M. W. Obiedziński

Faculty of Food Sciences, Warsaw University of Life Sciences, Nowoursynowska 159, 02-776 Warsaw, Poland

e-mail: marcin.bryla@ibprs.pl
}

Keywords Trichothecenes $\cdot$ Fusarium toxins $\cdot$ Ion trap LC-MS/MS · Grain products · Cleanup

\section{Introduction}

Trichothecenes are mycotoxins produced by various Fusarium fungi such as Fusarium sporotrichioides (the T-2 toxin and other trichothecenes), Fusarium graminearum, Fusarium culmorum and Fusarium crookwellense (deoxynivalenol (DON), nivalenol (NIV), fusarenon (FUS-X)). They are the most often encountered mycotoxins in cereal grains. Many hot spots of contamination with Fusarium-produced mycotoxins in wheat and maize grains have been located in China, India and USA (Charlton and Holstege 2010).

The trichothecin toxin compound itself was for the first time isolated from Trichothecium roseum and described by Freeman and Morrison (1948). Later isolated trichothecenes included diacetoxyscirpenol (DAS), the T-2 toxin, NIV and DON. More than 180 various trichothecenes and their derivatives have been characterized so far from which the T-2, HT2 toxins and NIV exhibit the largest toxicity among all of them (Yazar and Omurtag 2008).

Trichothecenes are multi-ring sesquiterpenes with a common 12,13-epoxytrichothecene ring (Krska et al. 2007; Yazar and Omurtag 2008; Monaci et al. 2011; Mateo et al. 2002). Because of some subtle but significant differences in basic chemical structures, they have been classified into four types referred to as types A, B, C and D trichothecenes, of which the first two are the most important ones (Berthiller et al. 2005; Charlton and Holstege 2010). Each type B trichothecene has at its C-8 position the carbonyl group, whilst the group is absent in type A trichothecenes. Type A trichothecenes include such compounds as scirpentriol, 15-monoacetoxyscirpenol, DAS, HT-2 and T-2 toxins, T-2 triol, T-2 tetraol and neosolaniol (NEO). Type B trichothecenes include such compounds as 
DON, 3- and 15-acetyl-deoxynivalenol (3- and 15-ADON), NIV and FUS-X. Basic chemical structure and functional groups of the most important trichothecenes are shown in Fig. 1 (Schollenberger et al. 2008).

DON is the most often encountered and studied trichothecene toxin. It is produced mainly by $F$ graminearum and $F$ culmorum (Dall'Asta et al. 2010). Even if DON is not particularly toxic, its low-to-moderate doses constantly find their way into human/animal organisms via food and feed chain (Mankeviciene 2010). Most severe problems brought about the toxin appear in animal breeding (Lauber et al. 2001; Mankeviciene 2010).

The $\mathrm{T}-2$ toxin is another mycotoxin frequently found in foodstuffs. It strongly inhibits the synthesis of DNA and RNA (Medina and Magan 2011), influences immunologic system, exhibits cytotoxicity (Lattanzio et al. 2008; Busman et al. 2011) and inhibits synthesis of proteins both in vivo and in vitro (Ingle et al. 2010; Medina and Magan 2011). Inhaled $\mathrm{T}-2$ toxin was 10 times more toxic than $\mathrm{T}-2$ toxin taken orally (Schwake-Anduschus et al. 2010; Ingle et al. 2010). Microflora present in gastrointestinal tract of every mammal converts T-2 toxin into several metabolites, mainly into the HT-2 toxin that is easily absorbed into the blood (Medina and Magan 2011). Therefore, toxic effects caused in vivo by HT-2 toxin are partly included in the evaluation of toxicity of T-2 toxin (Lattanzio et al. 2008; Busman et al. 2011; Medina and Magan 2011).

European Commission's Scientific Committee on Food (SCF) has specified tolerable daily intake (TDI) regarding some Fusarium mycotoxins, including TDI for DON, NIV and HT-2 and T-2 toxins equal to $1,0.7$ and $0.06 \mu \mathrm{g} / \mathrm{kg}$ of body weight, respectively. Hazard for human health posed by the Fusarium mycotoxins depends on the diet. Foodstuffs based on cereal grains (particularly wheat and maize) have been identified as the main source of trichothecenes (SCF 2002). The scientific cooperation research programme (SCOOP 2003) devoted to Fusarium mycotoxins in food consumed in European Union has shown that TDI limits for DON set for general public were not exceeded in population even if consumption of that toxin taken via food was close to the limits set for higher risk groups such as infants and small

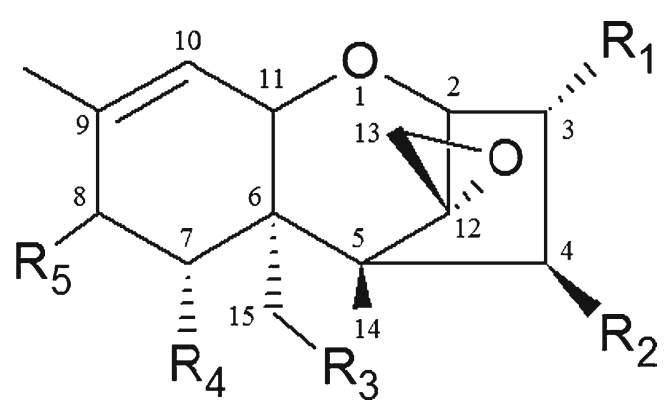

Fig. 1 Basic chemical structure and functional groups of the most important trichothecenes children. On the other hand, TDI limits for HT-2/T-2 toxins were exceeded.

Various chromatographic methods commonly used for quantitative determination of trichothecenes in cereal-based products include gas chromatography with electron capture, flame ionisation or mass spectrometry (MS) detectors (Nielsen and Thrane 2001; Schothorst and Jekel 2001; Ibáñez-Vea et al. 2011; Valle-Algarra et al. 2011) and highperformance liquid chromatography (HPLC) with ultraviolet, diode array, fluorescence or MS detectors (Jiménez et al 2000; Dall'Asta et al. 2004; Biancardi et al. 2005; Santini et al. 2009; Monaci et al. 2011). Liquid chromatography (LC)-MS spectrometers with triple quadrupole mass analysers have been most frequently used in labs dealing with trichothecene analyses. Development of an ion trap-based simultaneous method of type A and B trichothecene determination and its application to the analysis of the real-life samples brings an innovative element to the study framework.

\section{Materials and Methods}

Chemicals, Reagents and Standards

Reagents used in this work included HPLC-grade methanol and acetonitrile (ACN) (Rathburn Chemicals Ltd, Walkerburn, UK); acetic acid (POCH, Gliwice, Poland); ammonium acetate and charcoal (Sigma-Aldrich, St. Louis, MO, USA); water purified in a Hydrolab water treatment unit (Wiślina, Poland); and Extrelute ${ }^{\circledR}$ diatomaceous earth and neutral alumina (Merck, Darmstadt, Germany). Analytical standards and certified reference materials used in this work included Mycotoxin Mix 4 (A and B trichothecenes) $10 \mu \mathrm{gL}^{-1}$ (Biopure, Tulln, Austria); NEO $100 \mu \mathrm{g} \mathrm{mL}^{-1}$ (Biopure, Tulln, Austria); certified reference material BRM-003022-DON in wheat (Biopure, Tulln, Austria); and reference material RMM078-428r-HT-2 and T-2 toxins in durum wheat (Aokin, Berlin, Germany). Calibrating and working standards were prepared by dilution of analytical standards with methanol/ water/acetic acid solution (10:89.9:0.1).

\section{LC-MS/MS Apparatus}

Trichothecenes were determined using liquid chromatograph coupled with the LCQ Advantage Max mass detector (Thermo Scientific, Austin, TX, USA) equipped with an ion trap analyser. The 150/2 mm Nucleodur Sphinx RP $1.8 \mu \mathrm{m}$ chromatographic column (Macherey-Nagel, Düren, Germany) was used for separation. Two methanol/water solutions were used as the mobile phases: phase A $(20: 80)$ and phase B $(80: 20)$ to which ammonium acetate was added to $5 \mathrm{mM}$ of final concentration. Mobile phase flow rate was $0.15 \mathrm{~mL} \mathrm{~min}{ }^{-1}$. The following gradient was applied: $0-4 \mathrm{~min} 80 \% \mathrm{~A} ; 10-13 \mathrm{~min}$ 
$60 \% \mathrm{~A} ; 15-25 \min 15 \% \mathrm{~A} ; 30-38 \min 100 \% \mathrm{~B}$; and $42-$ $60 \min 80 \% \mathrm{~A}$. The mass spectrometer was operated in the positive/negative electrospray ionisation mode (ESI). A nebulizing gas (nitrogen) flow rate of 25 arbitrary units (a.u.), auxiliary gas (nitrogen) flow rate of 10 a.u., atomizer bias voltage of $5 \mathrm{kV}$, capillary temperature of $260^{\circ} \mathrm{C}$ and capillary bias voltage of $34 \mathrm{~V}$ were used. Helium was used as the ion trap collision gas. Precursor ions, fragmentation ions and some other mass spectrometer parameters are shown in Table 1.

\section{Samples and Sample Treatment}

Ninety-four grain-based food products available in the local market were purchased in different supermarkets. They included the most often consumed cereal products made of basic grains: wheat (35 products), maize (21 products), rye (14 products), barley (12 products) and oat (12 products).

Samples were ground in a laboratory mill and/or thoroughly mixed before analysis. Five grams sample was homogenized with the mixture of $50 \mathrm{~mL}$ of $\mathrm{ACN} /$ water solution (84:16) for $2 \mathrm{~min}$. The entire mixture was transferred into a centrifuge tube and centrifuged for $10 \mathrm{~min}$ at an acceleration of $10,730 \times \mathrm{g}$. The supernatant was transferred to a separator and extracted with $50 \mathrm{~mL}$ of hexane to eliminate lipids. The water/ACN phase was collected, and $20 \mathrm{~mL}$ of the extract was cleaned up using some earlier prepared 6-mL volume columns protected with frits. Each such column was filled with $0.1 \mathrm{~g}$ of diatomaceous earth covered with $0.7 \mathrm{~g}$ of the charcoal/ Extrelute/neutral alumina (2:1:1) mixture. The column was activated with $20 \mathrm{~mL}$ of ACN/water mixture (84:16). The extract was transferred on such a column and eluted with $15 \mathrm{~mL}$ of the same mixture. The eluate was evaporated in a BÜCHI rotary evaporator and dissolved in $1 \mathrm{~mL}$ of methanol/ water/acetic acid mixture (10:89.9:0.1). Fifty microliters of a standard or a sample was transferred into the HPLC chromatograph column via an auto-sampler. The acquired chromatographic data were processed using the Xcalibur 1.2 computer software. Samples were analysed in triplicates.

\section{Results and Discussion}

\section{LC-IT-MS Parameters}

The Nucleodur Sphinx RP $1.8 \mu$ m (Macherey-Nagel) column provided good chromatographic separation of the analysed mycotoxins. A methanol/water mixture is the most often used mobile phase for mycotoxin analyses. Some authors claim that acetonitrile-based phase is more selective and allows complete separation of some isomers (e.g. 3- and 15-ADON; Gentili et al. 2007). In our study, methanol-based mobile phase was chosen since it produced somewhat better ionisation of the analytes. Ammonium acetate was added to the phase in $5 \mathrm{mM}$ concentration to help increase ionisation efficiency. According to Santini et al. (2009) concentration of the added salt should not exceed $10 \mathrm{mM}$.

Ionisation conditions were optimized to attain maximum sensitivity for all analysed mycotoxins. To that end, analyte was directly injected to the MS spectrometer ion source using a syringe pump. The electrospray (ESI) technique in positive/ negative ionisation mode was used to produce pseudomolecular ions for mass spectrometry. Alternatively, the atmospheric pressure chemical ionisation (APCI) technique was also reported (Lattanzio et al. 2008; Suman and Catellani 2008). According to Lattanzio et al. (2008), ESI was a better choice for type B trichothecenes (when negative pseudomolecular ions are produced), while APCI was better for type A trichothecenes (when positive pseudo-molecular ions are produced).

Precursor ions created adducts with acetate ions (NIV, DON, FUS-X, 3-ADON) or with ammonia ions (NEO, DAS, HT-2 and T-2 toxins). A single transition was monitored for every analyte. The optimized ionisation conditions included collision energy (EC), activation $\mathrm{Q}$, ion injection time, nebulizer bias voltage, capillary bias voltage and capillary temperature.

Ion source temperature had to be adjusted not only to sample type, but also to mobile phase flow rate. A too low

Table 1 MS/MS precursor ions/fragmentation ions and optimal ionisation parameters for individual mycotoxins

\begin{tabular}{|c|c|c|c|c|c|c|c|c|c|}
\hline Compound & Precursor ion $\mathrm{m} / \mathrm{z}$ & $\begin{array}{l}\text { Fragmentation } \\
\text { ion }(\mathrm{m} / \mathrm{z})\end{array}$ & $\begin{array}{l}\text { Collision } \\
\text { energy } \\
\text { EC }(\%)\end{array}$ & $\begin{array}{l}\text { Activation } \\
\text { value } Q\end{array}$ & $\begin{array}{l}\text { Activation } \\
\text { time (ms) }\end{array}$ & $\begin{array}{l}\text { Ion injection } \\
\text { time }(\mathrm{ms})\end{array}$ & $\begin{array}{l}\text { Number of } \\
\mu \text {-scans }\end{array}$ & $\begin{array}{l}\text { Nebulizer } \\
\text { voltage }[\mathrm{kV}]\end{array}$ & $\begin{array}{l}\text { Capillary } \\
\text { voltage [V] }\end{array}$ \\
\hline NIV & $371.0\left[\mathrm{M}+\mathrm{CH}_{3} \mathrm{COO}^{-}\right]^{-}$ & $310.9 ; 281.1$ & 22 & 0.254 & 30 & 220 & 5 & 5.7 & -8.0 \\
\hline DON & $355.0\left[\mathrm{M}+\mathrm{CH}_{3} \mathrm{COO}^{-}\right]^{-}$ & 294.9 & 22 & 0.250 & 30 & 200 & 5 & 5.7 & -8.0 \\
\hline FUS-X & $413.2\left[\mathrm{M}+\mathrm{CH}_{3} \mathrm{COO}^{-}\right]^{-}$ & 352.9 & 23 & 0.247 & 30 & 215 & 5 & 5.7 & -8.0 \\
\hline NEO & $400.0\left[\mathrm{M}+\mathrm{NH}_{4}^{+}\right]^{+}$ & $364.68 ; 305.0 ; 244.9$ & 22 & 0.250 & 30 & 225 & 5 & 5.0 & 23.0 \\
\hline 3-ADON & $397.1\left[\mathrm{M}+\mathrm{CH}_{3} \mathrm{COO}^{-}\right]^{-}$ & 336.9 & 27 & 0.255 & 30 & 220 & 5 & 5.7 & -8.0 \\
\hline DAS & $384.2\left[\mathrm{M}+\mathrm{NH}_{4}^{+}\right]^{+}$ & $307.0 ; 349.0$ & 26 & 0.249 & 30 & 220 & 5 & 5.0 & 23.0 \\
\hline HT-2 toxin & $442.0\left[\mathrm{M}+\mathrm{NH}_{4}^{+}\right]^{+}$ & $424.9 ; 263.0$ & 25 & 0.250 & 30 & 220 & 5 & 5.0 & 33.5 \\
\hline $\mathrm{T}-2$ toxin & $484.0\left[\mathrm{M}+\mathrm{NH}_{4}^{+}\right]^{+}$ & 305.0 & 28 & 0.250 & 30 & 225 & 5 & 5.0 & 33.5 \\
\hline
\end{tabular}


temperature caused the sample to fail to evaporate completely, while a too high temperature degraded the analytes. Signal-tonoise ratio $(S / N)$ was found to be optimal at a capillary temperature equal to $260^{\circ} \mathrm{C}$ and mobile phase flow rate equal to $0.15 \mathrm{~mL} \mathrm{~min}^{-1}$.

Type A and type B trichothecenes are usually determined by LC-MS/MS tandems equipped with triple quadrupole analysers, more rarely with ion trap analysers (Lattanzio et al. 2008; Suman and Catellani 2008). We have used an ion trap analyser (the LC-ion trap (IT)-MS technique). Disadvantages of this technique include the space charge effect: ion trap cannot hold too many ions or else they will mutually interact degrading analyser sensitivity and/or precision. Therefore, any unwanted ions from sample matrix must be eliminated as much as possible; in other words, samples must be carefully cleaned (Roszko et al. 2012). However, triple quadrupole analysers also have their limitations, mostly regarding their dynamic range, mass resolution and measurement precision (Suman and Catellani 2008). According to some authors, method sensitivity, linearity and precision attainable in ion trap-based MS spectrometers may be comparable to those attainable in triple quadrupole-based ones (Reemtsma 2001). The LC-IT-MS technique has already been used for quantitative determination of Fusarium toxins (Suman and Catellani 2008; Bryła et al. 2013). It seems that the LC-IT-MS technique attracts more and more interest of those concerned with analyses of various contaminants in foodstuffs.

\section{Clean-up}

Various solvents or mixtures of solvents are recommended by numerous authors as optimal to efficiently extract trichothecenes from samples of grain-based food and feed (Valle-
Algarra et al. 2005; Stecher et al. 2007; Cano-Sancho et al. 2011; Schothorst and Jekel 2001). The mixture of acetonitrile/ water (84:16) is a popular choice and was used during the study.

To get rid of lipids in the analysed samples, the extraction with non-polar solvent as $n$-hexane was used (Langseth and Rundberget 1998).

Chromatographic columns with stationary beds composed of silica gel, alumina, florisil and charcoal are very often used to clean up extracts (Langseth and Rundberget 1998). Beds based on alumina/charcoal or combinations of alumina/ charcoal/Extrelute have been pretty long used to separate DON and other trichothecenes from food product matrices (Romer 1986). Various applied proportions of individual adsorbents resulted in various attained recoveries and precision levels (Omurtag and Beyoğlu 2007; Perkowski et al. 2003; Valle-Algarra et al. 2005, 2011).

Figure 2 shows recoveries of selected trichothecenes obtained during the study for four different compositions of the adsorbing mixture. The best - and quite satisfactoryvalues were obtained for alumina/charcoal/Extrelute mixed in the 1:2:1 proportion. We have also experimentally verified that $15 \mathrm{~mL}$ of $\mathrm{ACN} / \mathrm{H}_{2} \mathrm{O}(84: 16)$ mixture was needed to totally elute analytes from the adsorbent. Typical profile of the eluted trichothecenes is shown in Fig. 3.

\section{Method Validation}

Chromatographic peak areas vs. concentration of standards were charted as calibration curves for individual compounds. Standards of the concentration 16, 31, 63, 125, 250 and $500 \mathrm{\mu g} \mathrm{kg}^{-1}$ were used for all mycotoxins except NEO and DAS, for which $1,2,4,8,16,31,63,125$ and $250 \mu \mathrm{g} \mathrm{kg}^{-1}$ standards were used. Standards were prepared in methanol/ water/acetic acid solution (10:89.9:0.1). Equations of the

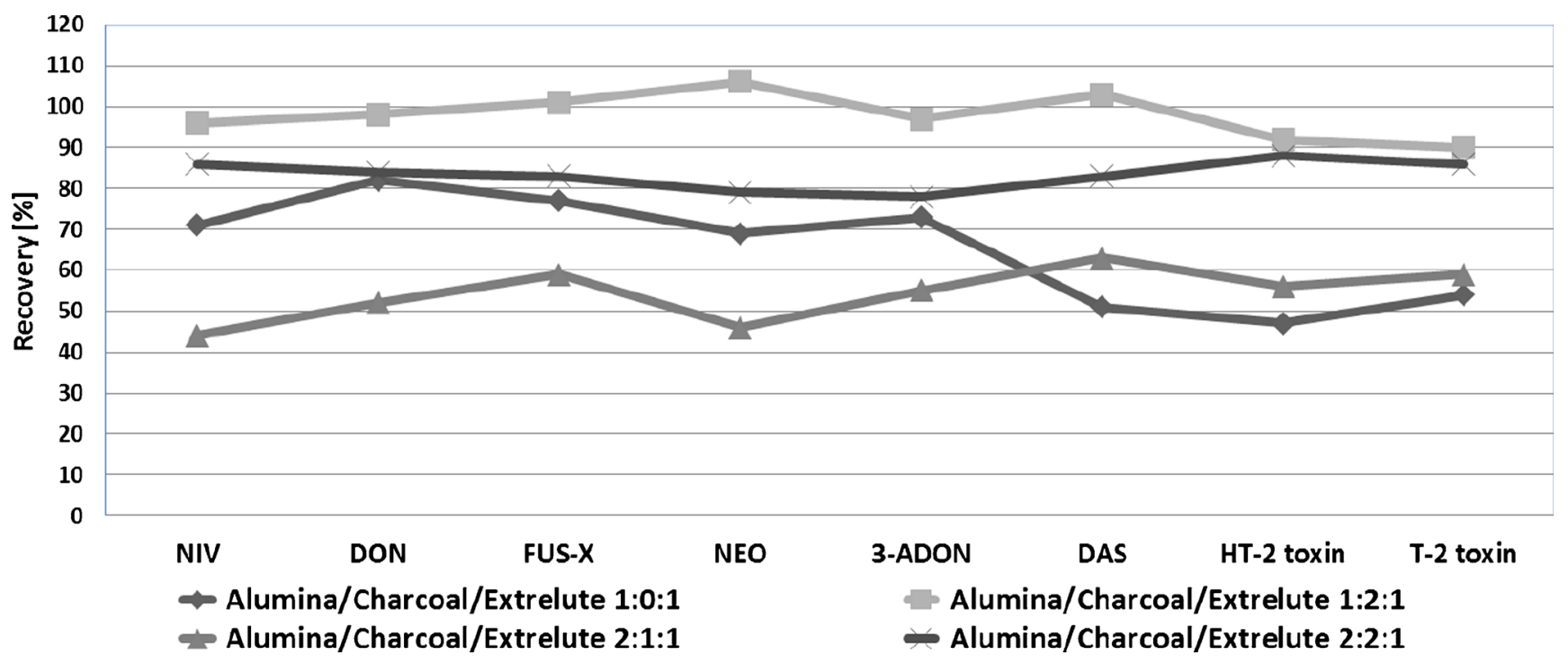

Fig. 2 Recoveries of selected trichothecenes for four different compositions of the adsorbing mixture 
Fig. 3 Profile of trichothecenes eluted from the 1:2:1 alumina/ charcoal/Extrelute

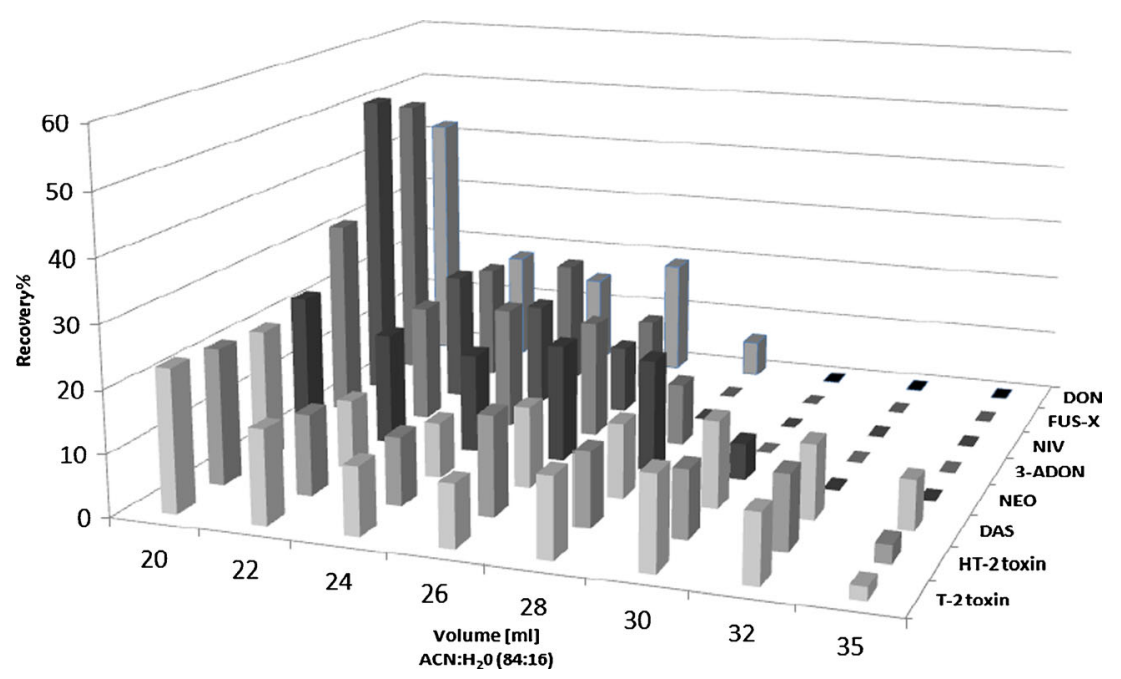

obtained calibration curves are shown in Table 2. For all of them, the correlation coefficients were above 0.9967 .

Limit of quantification (LOQ) of the method was $25 \mu \mathrm{g} \mathrm{kg}^{-1}$ for all mycotoxins except NEO $\left(2 \mu \mathrm{g} \mathrm{kg}^{-1}\right)$ and DAS $\left(1 \mu \mathrm{g} \mathrm{kg}^{-1}\right)$ (see Table 2). MS/MS chromatograms of each toxin at its LOQ concentration level are shown in Fig. 4.

Method validation experiment was carried out on wheat flour and maize grain samples. Several 10-g samples earlier tested for the absence of analysed toxins were spiked with 0.3 , 0.5 and $1 \mathrm{~mL}$ of standard solution of the mycotoxins mixture at a concentration of $5 \mu \mathrm{g} \mathrm{mL}^{-1}$.

The resulting fortification levels were 150, 250 and $500 \mu \mathrm{g} \mathrm{kg}^{-1}$, respectively. Recovery rates were calculated in relation to standards dissolved in matrix solutions to eliminate matrix effects responsible for suppression of signals from analyte ions (Table 3 ). The average recovery rates (depending of the fortification level) ranged from 88 to $125 \%$, and relative standard deviation was generally below $20 \%$, except one case for NEO getting $27.4 \%$ (see Table 4).

Two certified reference materials were used in the method validation experiment. Durum wheat sample with certified concentration of HT-2 + T-2 toxins equal to $149.76 \mu \mathrm{g} \mathrm{kg}^{-1}$ (RMM-078-428r) has specified the range of acceptable results as $85.998-213.520 \mu \mathrm{g} \mathrm{kg}^{-1}$. The average sum of HT-2 and T-2 toxin concentration obtained for 10 independent analyses was $165 \mu \mathrm{g} \mathrm{kg}^{-1}$ and laid within the range of certified value. Similarly, the average DON concentration obtained for six independent analyses was $939 \pm 47 \mu \mathrm{g} \mathrm{kg}^{-1}$. It was within the specified range of certified concentration of DON in wheat durum (BRM-003022; equal to $877 \pm 23 \mu \mathrm{g} \mathrm{kg}^{-1}$ ), included uncertainty of measurement.

\section{Application of the Developed Method}

Using the described method above, the concentrations of selected trichothecenes were determined in 94 grain-based food products. All analysed mycotoxins except NIV and FUS-X were found. DON was found in all groups of the tested products in $63 \%$ of analysed samples at the $272 \pm$ $358-\mu \mathrm{g} \mathrm{kg}^{-1}$ average level.

Most frequently, Fusarium toxins were found in maizebased products (Table 4). DON, NEO, 3-ADON, DAS, HT-2 and T-2 toxins were found in the tested samples. Seventy-six percent of the maize products contained DON for which concentrations were among the highest one, i.e. $476 \pm$
Table 2 Calibration curve parameters, LOQ and LOD for individual mycotoxins

\begin{tabular}{lllll}
\hline Compound & $\begin{array}{l}\text { Calibration curve } \\
\text { equation }\end{array}$ & $\begin{array}{l}\text { Correlation } \\
\text { coefficient }\left(R^{2}\right)\end{array}$ & $\begin{array}{l}\text { Limit of quantification, } \\
\text { LOQ }\left[\mu \mathrm{kg}^{-1}\right]\end{array}$ & $\begin{array}{l}\text { Limit of detection, } \\
\text { LOD }\left[\mu \mathrm{kg}^{-1}\right]\end{array}$ \\
\hline NIV & $Y=9,791.48 X$ & 0.9992 & 25 & 10 \\
DON & $Y=8,218.02 X$ & 0.9988 & 25 & 10 \\
FUS-X & $Y=8,337.87 X$ & 0.9967 & 25 & 10 \\
NEO & $Y=263,426.00 X$ & 0.9985 & 2 & 0.5 \\
3-ADON & $Y=5,458.94 X$ & 0.9967 & 25 & 10 \\
DAS & $Y=569,578.00 X$ & 0.9978 & 1 & 0.3 \\
HT-2 toxin & $Y=39,028.90 X$ & 0.9975 & 25 & 10 \\
T-2 toxin & $Y=67,512.90 X$ & 0.9995 & 25 & 10 \\
\hline
\end{tabular}




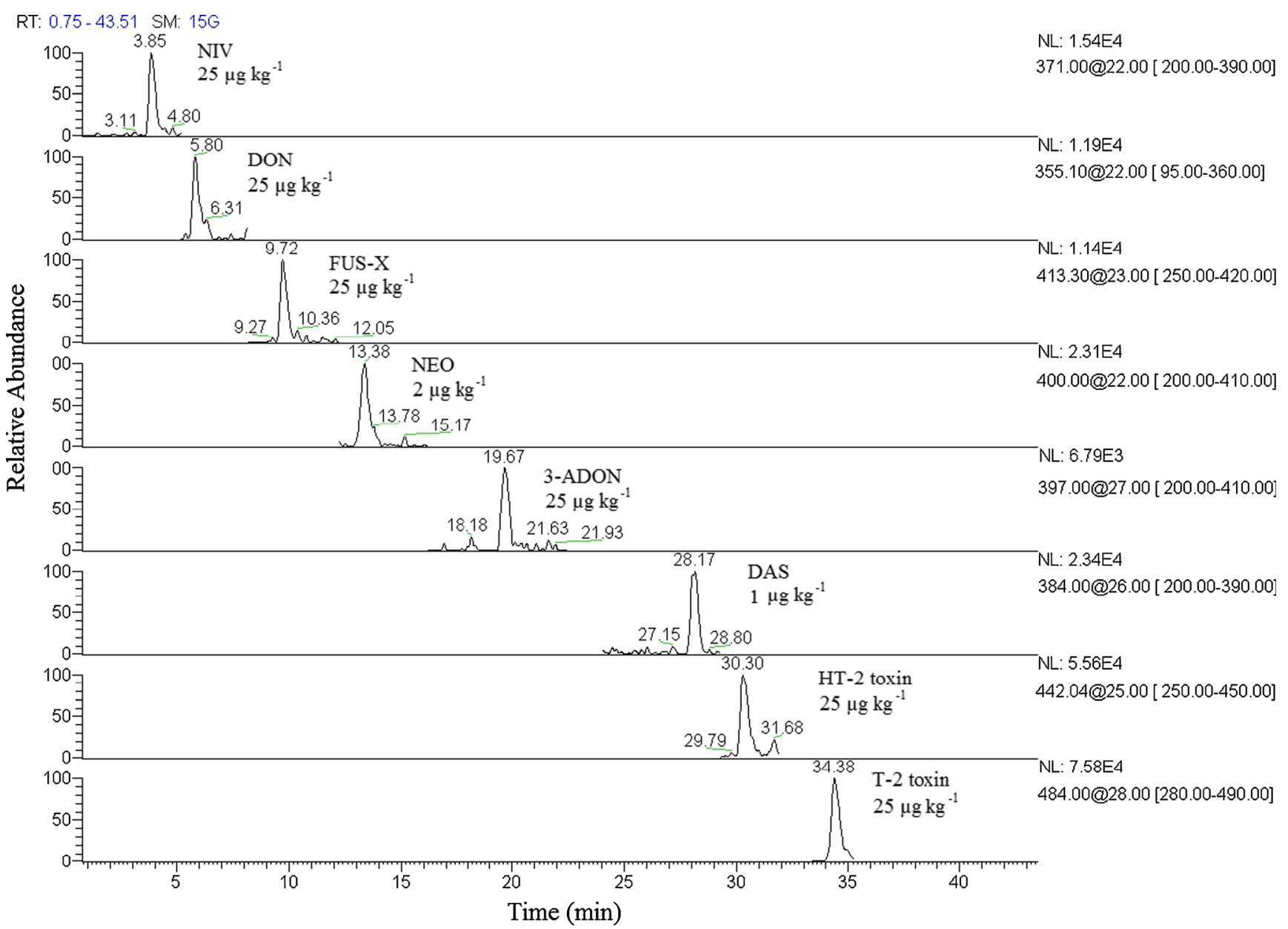

Fig. 4 MS/MS chromatographs of individual trichothecenes in their LOQ concentrations

$471 \mu \mathrm{g} \mathrm{kg}^{-1}$ on the average. Other mycotoxins were found much less frequently, and their average levels were also much lower, i.e. they did not exceed $26 / 37 / 37 / 4 / 3 \mu \mathrm{g} \mathrm{kg}^{-1}$ for 3-ADON/HT-2 toxin/T-2 toxin/NEO/DAS, respectively.

Table 3 Method recovery (R\%) and method precision (expressed by RSD\%) for individual mycotoxins

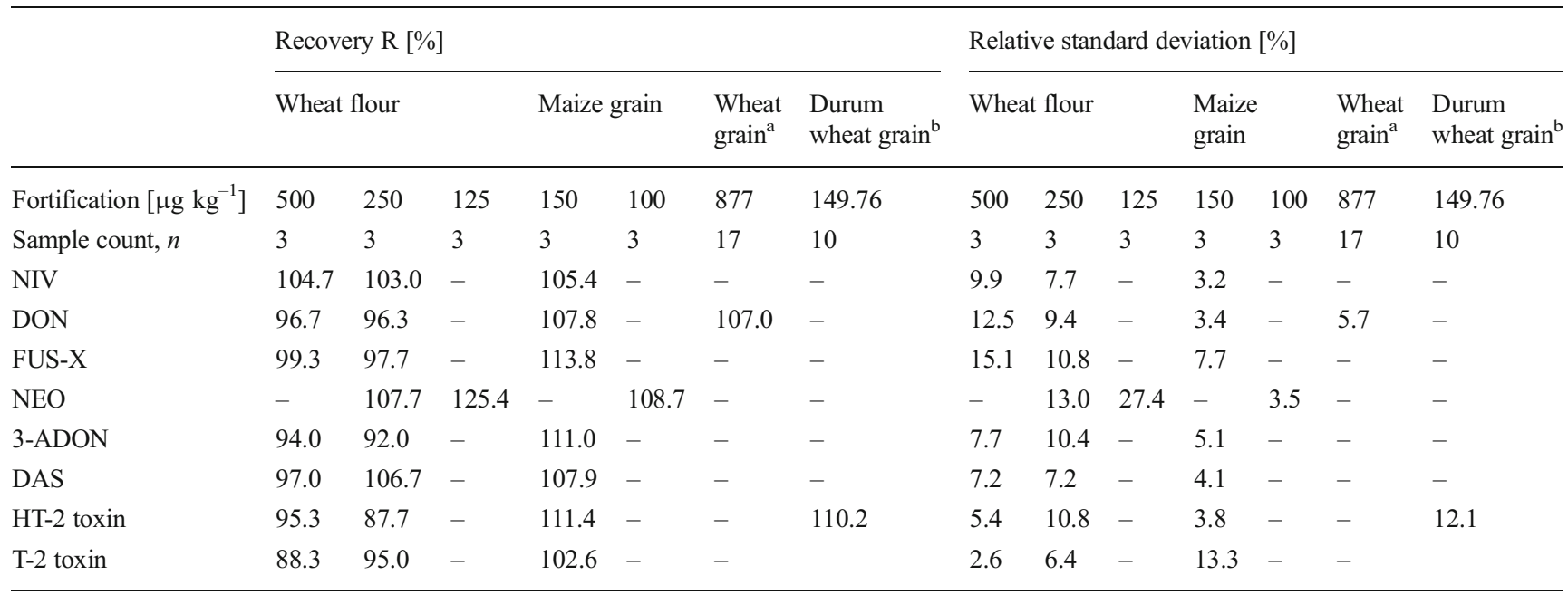

${ }^{\mathrm{a}} \mathrm{DON}$ in wheat reference material

${ }^{\mathrm{b}}$ HT-2 and T-2 toxins in durum wheat reference material 
Table 4 Trichothecenes found in grain-based food products tested in this work

\begin{tabular}{|c|c|c|c|c|c|c|c|c|c|}
\hline \multicolumn{2}{|c|}{ Corn (sample count, $n$ ) } & \multirow{2}{*}{$\frac{\text { NIV }}{-{ }^{\mathrm{a}}}$} & \multirow{2}{*}{$\begin{array}{l}\text { DON } \\
29(83 \%)\end{array}$} & \multirow{2}{*}{$\begin{array}{l}\text { FUS-X } \\
-\end{array}$} & \multirow{2}{*}{$\begin{array}{l}\text { NEO } \\
1(3 \%)\end{array}$} & \multirow{2}{*}{$\frac{3-\mathrm{ADON}}{1(3 \%)}$} & \multirow{2}{*}{$\begin{array}{l}\text { DAS } \\
4(11 \%)\end{array}$} & \multirow{2}{*}{$\begin{array}{l}\text { HT-2 toxin } \\
1(3 \%)\end{array}$} & \multirow{2}{*}{$\begin{array}{l}\text { T-2 toxin } \\
-\end{array}$} \\
\hline Wheat $(n=35)$ & Number (fraction) of positive samples & & & & & & & & \\
\hline & Median & - & 152 & - & $3^{\mathrm{b}}$ & $61^{\mathrm{b}}$ & 2 & $24^{\mathrm{b}}$ & - \\
\hline & Average \pm SD & - & $249 \pm 303$ & - & $3^{b} \pm 1$ & $59^{\mathrm{b}} \pm 8$ & $2 \pm 1$ & $26^{\mathrm{b}} \pm 6$ & - \\
\hline & Min & - & 29 & - & 3 & 47 & 1 & 21 & - \\
\hline & $\operatorname{Max}$ & - & 1,538 & - & 4 & 65 & 2 & 34 & - \\
\hline \multirow[t]{5}{*}{ Maize $(n=21)$} & Number (fraction) of positive samples & - & $16(76 \%)$ & - & $4(19 \%)$ & $6(29 \%)$ & $6(29 \%)$ & $2(10 \%)$ & $2(10 \%)$ \\
\hline & Median & - & 349 & - & 3 & 25 & 2 & 36 & 36 \\
\hline & Average \pm SD & - & $476 \pm 471$ & - & $4 \pm 2$ & $31 \pm 12$ & $3 \pm 3$ & $36 \pm 7$ & $36 \pm 11$ \\
\hline & Min & - & 51 & - & 2 & 25 & 1 & 29 & 25 \\
\hline & Max & - & 2,026 & - & 7 & 58 & 9 & 42 & 47 \\
\hline \multirow[t]{5}{*}{ Rye $(n=14)$} & Number (fraction) of positive samples & - & $9(64 \%)$ & - & - & - & - & - & - \\
\hline & Median & - & 60 & - & - & - & - & - & - \\
\hline & Average $\pm \mathrm{SD}$ & - & $66 \pm 39$ & - & - & - & - & - & - \\
\hline & Min & - & 25 & - & - & - & - & - & - \\
\hline & Max & - & 165 & - & - & - & - & - & - \\
\hline \multirow[t]{5}{*}{ Barley $(n=12)$} & Number (fraction) of positive samples & - & $4(33 \%)$ & - & - & - & - & - & - \\
\hline & Median & - & 40 & - & - & - & - & - & - \\
\hline & Average \pm SD & - & $46 \pm 20$ & - & - & - & - & - & - \\
\hline & Min & - & 27 & - & - & - & - & - & - \\
\hline & Max & - & 77 & - & - & - & - & - & - \\
\hline \multirow[t]{5}{*}{ Oats $(n=12)$} & Number (fraction) of positive samples & - & $1(8 \%)$ & - & - & - & - & $3(25 \%)$ & - \\
\hline & Median & - & $162^{\mathrm{b}}$ & - & - & - & - & 27 & - \\
\hline & Average \pm SD & - & $158^{\mathrm{b}} \pm 17$ & - & - & - & - & $30 \pm 5$ & - \\
\hline & Min & - & 142 & - & - & - & - & 26 & - \\
\hline & $\operatorname{Max}$ & - & 174 & - & - & - & - & 38 & - \\
\hline
\end{tabular}

All concentrations are in micrograms per kilogram

a $<$ LOQ

${ }^{\mathrm{b}}$ Median and average value calculated for an individual sample analysed in triplicate

Eighty-three percent of wheat-based products contained DON at the average level of $249 \mu \mathrm{g} \mathrm{kg}^{-1}$. Other mycotoxins were found much less frequently, i.e. 3-ADON in only one sample at the $59-\mu \mathrm{g} \mathrm{kg}^{-1}$ level, NEO, HT-2 toxin and DAS in a few samples with the average concentrations close to respective LOQs.

Among 12 tested samples of oat-based products, DON was found at a low level in only one sample, while HT-2 toxin was found only in three samples.

DON was also found in 9 out of 14 tested samples of ryebased products $(64 \%)$ at an average level of $66 \mu \mathrm{g} \mathrm{kg}^{-1}$ and in 4 out of 12 tested samples of barley-based products (33\%) at an average level of $46 \mu \mathrm{g} \mathrm{kg}^{-1}$. No other mycotoxins were found in those samples.

MS/MS chromatograms of trichothecenes extracted from the tested grain-based products are shown in Fig. 5.

DON is definitely the most frequently identified trichothecene in food products tested across the world for mycotoxins. Also, the levels of DON are definitely higher than the levels of other identified trichothecenes.
Typical Literature Data DON was identified in $38 \%$ of 148 tested samples of grain food products from Spanish market at levels of 31.5-468 $\mathrm{g} \mathrm{kg}^{-1}$. FUS-X was found only in $1.3 \%$ samples and NIV only in $2.7 \%$ samples at levels below $57 \mu \mathrm{g} \mathrm{kg}^{-1}$. 3-ADON was not identified at all (Montes et al. 2012).

DON was identified in $95 \%$ of 123 tested samples of Spanish barley grain at an average level of $59.6 \mu \mathrm{g} \mathrm{kg}^{-1}$. Fractions of samples contaminated with NIV, 3-ADON, DAS, FUS-X, HT-2 and T-2 toxins were 20, 28, 25, 2, 24, and $10 \%$, respectively. Average concentrations of the found toxins did not exceed $35 \mu \mathrm{g} \mathrm{kg}^{-1}$ (Ibáñez-Vea et al. 2012).

DON at levels above $20 \mathrm{\mu g} \mathrm{kg}^{-1}$ was identified in $31 \%$ of 449 samples of cereal grain (wheat, barley, oats) (Langseth and Rundberget 1999). Fractions of samples contaminated with NIV, HT-2 and T-2 toxins were 5, 33 and $13 \%$, respectively. The average contents of NIV, HT-2 and T-2 toxins were 49,107 and $62 \mu \mathrm{g} \mathrm{kg}^{-1}$, respectively.

Representative (289) samples of wheat-, rye- and oat-based food products available in the German market were tested by 


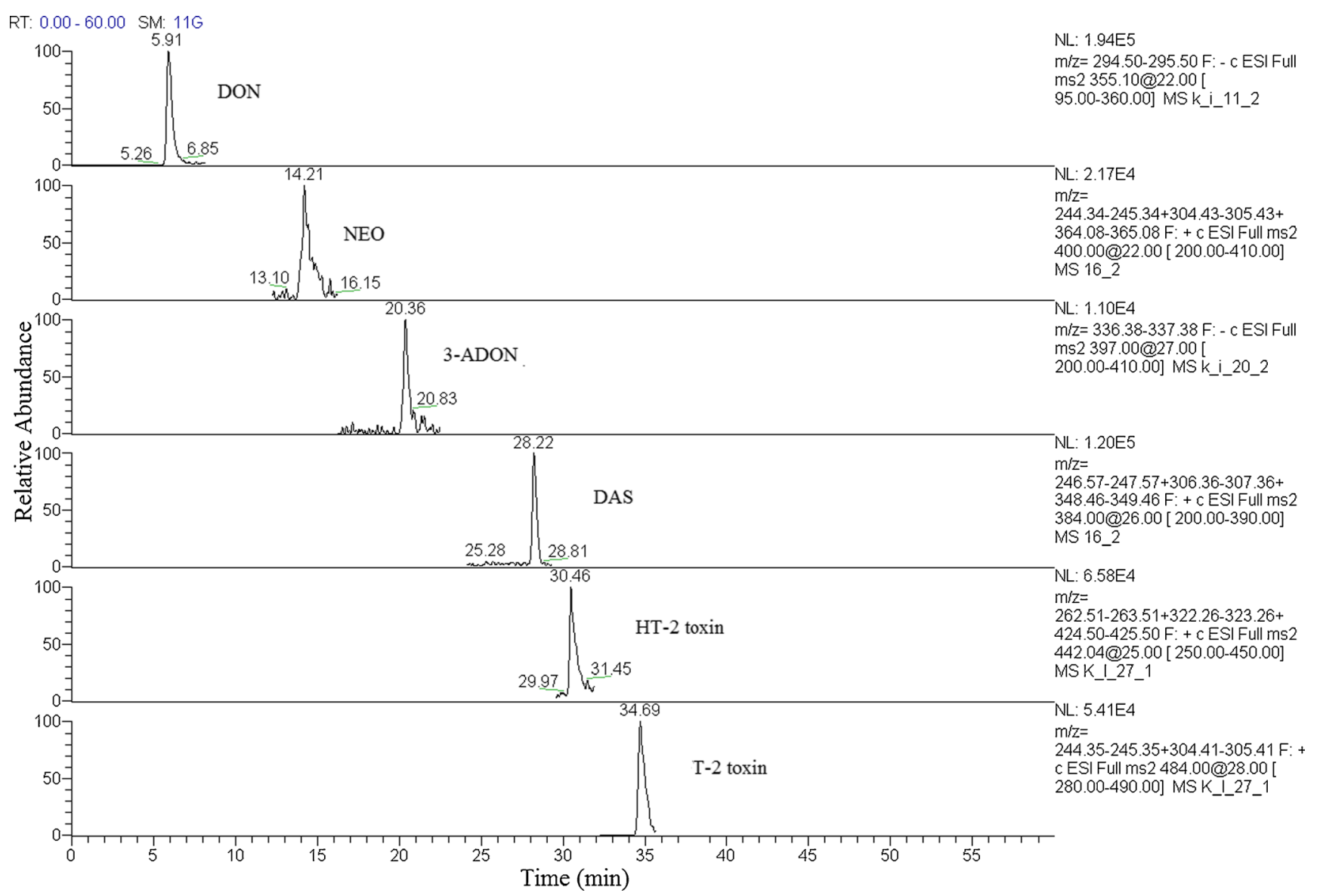

Fig. $5 \mathrm{MS} / \mathrm{MS}$ chromatograms of trichothecenes extracted from the tested grain-based products

Gottschalk et al. (2009). DON was identified in all tested samples of wheat-based food products and in $74 \%$ samples of oat-based food products at average levels below $58 \mu \mathrm{g} \mathrm{kg}^{-1}$. Also, the $\mathrm{T}-2$ toxin was identified in all tested samples of oat-based products. The FUS-X, NIV, NEO, 3ADON, DAS and HT-2 toxin were found at very low average concentrations of $0.01-10 \mu \mathrm{g} \mathrm{kg}^{-1}$. It must be pointed out that LOQs of the analytical method applied by the authors were extremely low.

To sum up, concentrations of trichothecenes found in food products tested in this work were generally comparable to those reported by majority of other authors.

\section{Conclusions}

An LC-IT-MS spectrometer with an ion trap has been successfully used in this work to determine eight selected trichothecenes. Analytes extracted from the matrix were cleaned using neutral alumina/charcoal/diatomaceous earth mixtures. The clean-up procedure has been experimentally optimized. The obtained recovery rates were $88-125 \%$, depending on the toxin, matrix and fortification level. Relative standard deviation (a measure of method precision) was within the 2.6-27.4\% range.

Using the described method, the concentrations of selected trichothecenes in 94 grain-based food products made of wheat, maize, rye, barley and oats were determined. All analysed mycotoxins except NIV and FUS-X were found. DON was found in all tested product groups in $63 \%$ of analysed samples at the $272 \pm 358-\mu \mathrm{g} \mathrm{kg}^{-1}$ average level.

Most frequently, Fusarium toxins were found in maizeand wheat-based products. DON was found in $76 \%$ of maizebased products with the average concentration equal to $476 \pm$ $471 \mu \mathrm{g} \mathrm{kg}^{-1}$, which was the highest one. The lower DON concentration with the average level of $249 \mu \mathrm{g} \mathrm{kg}^{-1}$ was observed in $83 \%$ of tested wheat samples.

Other mycotoxins were found much less frequently. Rye-, barley- and oat-based products were the least contaminated with the studied trichothecenes.

Conflict of Interest Marcin Bryła declares that he has no conflict of interest. Renata Jędrzejczak declares that he has no conflict of interest. Krystyna Szymczyk declares that he has no conflict of interest. Marek Roszko declares that he has no conflict of interest. Mieczysław W. Obiedziński declares that he has no conflict of interest. This article does not contain any studies with human or animal subjects. 
Open Access This article is distributed under the terms of the Creative Commons Attribution License which permits any use, distribution, and reproduction in any medium, provided the original author(s) and the source are credited.

\section{References}

Berthiller F, Schumacher R, Buttinger G, Krska R (2005) Rapid simultaneous determination of major type A- and B-trichothecenes as well as zearalenone in maize by high performance liquid chromatography-tandem mass spectrometry. J Chromatogr A 1062:209-216

Biancardi A, Gasparini M, Dall'asta C, Marchelli R (2005) A rapid multiresidual determination of type A and type $\mathrm{B}$ trichothecenes in wheat flour by HPLC-ESI-MS. Food Addit Contam 22(3):251-258

Bryła M, Jedrzejczak R, Roszko M, Szymczyk K, Obiedziński MW, Sękul J, Rzepkowska M (2013) Application of molecularly imprinted polymers to determine B1, B2, and B3 fumonisins in cereal products. J Sep Sci 36(3):578-584

Busman M, Poling SM, Maragos CM (2011) Observation of T-2 toxin and HT-2 toxin glucosides from Fusarium sporotrichioides by liquid chromatography coupled to tandem mass spectrometry (LCMS/MS). Toxins 3:1554-1568

Cano-Sancho G, Valle-Algarra FM, Jiménez M, Burdaspal P, Legarda TM, Ramos AJ, Sanchis V, Marín S (2011) Presence of trichothecenes and co-occurrence in cereal-based food from Catalonia (Spain). Food Control 22:490-495

Charlton NP, Holstege ChP. (2010). Chapter 20. The myco-agents of bioterrorism. In: Mycotoxins in food, feed and bioweapons. Springer-Verlag, Berlin, pp. 353-365

Dall'Asta C, Galaverna G, Biancardi A, Gasparini M, Sforza S, Dossena A, Marchelli R (2004) Simultaneous liquid chromatography-fluorescence analysis of type $\mathrm{A}$ and type $\mathrm{B}$ trichothecenes as fluorescent derivatives via reaction with coumarin-3-carbonyl chloride. J Chrom A $1047(2): 241-247$

Dall'Asta Ch, Galaverna G, Dossena A, Sforza S, Marchelli R. (2010). Chapter 22. Masked mycotoxins and mycotoxin derivatives in food: the hidden menace. In: Mycotoxins in food, feed and bioweapons. Springer-Verlag, Berlin, pp. 385-395.

Freeman GG, Morrison RI (1948) Trichothecin: an antifungal metabolic product of Trichothecium roseum. Nature 162(4105):30

Gentili A, Caretti F, D'Ascenzo G, Rocca LM, Marchese S, Materazzi S, Perret D (2007) Simultaneous determination of trichothecenes A, B, and D in maize food products by LC-MS-MS. Chromatographia 66(9-10):669-676

Gottschalk C, Barthel J, Engelhardt G, Bauer J, Meyer K (2009) Simultaneous determination of type A, B and D trichothecenes and their occurrence in cereals and cereal products. Food Addit Contam 26(9):1273-1289

Ibáñez-Vea M, Lizarraga E, González-Peñas E (2011) Simultaneous determination of type-A and type-B trichothecenes in barley samples by GC-MS. Food Control 22:1428-1434

Ibáñez-Vea M, Lizarraga E, González-Peñas E, López de Cerain A (2012) Co-occurrence of type-A and type-B trichothecenes in barley from a northern region of Spain. Food Control 25:81-88

Ingle A, Varma A, Rai M. (2010). Chapter 17. Trichothecenes as toxin and bioweapons: prevention and control. In: Mycotoxins in food, feed and bioweapons. Springer-Verlag, Berlin

Jiménez M, Mateo JJ, Mateo R (2000) Determination of type A trichothecenes by high-performance liquid chromatography with coumarin-3-carbonyl chloride derivatisation and fluorescence detection. J Chromatogr A 870:473-481

Krska R, Welzig E, Boudra H (2007) Analysis of Fusarium toxins in feed. Anim Feed Sci Technol 137:241-264
Langseth W, Rundberget T (1998) Instrumental methods for determination of nonmacrocyclictrichothecenes in cereals, foodstuffs and cultures. J Chromatogr A 815:103-121

Langseth W, Rundberget T (1999) The occurrence of HT-2 toxin and other trichothecenes in Norwegian cereals. Mycopathologia 147:157-165

Lattanzio VMT, Solfrizzo M, Visconti A (2008) Determination of trichothecenes in cereals and cereal-based products by liquid chromatography-tandem mass spectrometry. Food Addit Contam 25(3):320-330

Lauber U, Dillenburger T, Drochner W (2001) Distinct effects of equal levels of Fusarium toxins (Deoxynivalenol) in growing pigs. Possible reasons. Mycotoxin Res 17(1):53-57

Mankeviciene A (2010) Mycotoxins in Lithuanian cereals and grain products. Mycotoxins Food Feed Bioweapons 10:147-160

Mateo JJ, Mateo R, Jimenez M (2002) Accumulation of type A trichothecenes in maize, wheat and rice by Fusarium sporotrichioides isolates under diverse culture conditions. Int J Food Microbiol 72: $115-123$

Medina A, Magan N (2011) Temperature and water activity effects on production of T-2 and HT-2 by Fusarium langsethiae strains from north European countries. Food Microbiol 28:392-398

Monaci L, De Angelis E, Visconti A (2011) Determination of deoxynivalenol, T-2 and HT-2 toxins in a bread model food by liquid chromatography-high resolution-Orbitrap-mass spectrometry equipped with a high-energy collision dissociation cell. J Chromatogr 1218:8646-8654

Montes R, Segarra R, Castillo MA (2012) Trichothecenes in breakfast cereals from the Spanish retail market. J Food Compos Anal 27:38-44

Nielsen K, Thrane U (2001) Fast methods for screening of trichothecenes in fungal cultures using gas chromatography-tandem mass spectrometry. J Chrom A 929(1-2):75-87

Omurtag GZ, Beyoğlu D (2007) Occurrence of deoxynivalenol (vomitoxin) in beer in Turkey detected by HPLC. Food Control 18:163-166

Perkowski J, Kiecana I, Kaczmarek Z (2003) Natural occurrence and distribution of Fusarium toxins in contaminated barley cultivars. Eur J Plant Pathol 109:331-339

Reemtsma T (2001) The use of liquid chromatography-atmospheric pressure ionization-mass spectrometry in water analysis. II Obstacles Trends Anal Chem 20:533-542

Romer TR (1986) Use of small charcoal/alumina cleanup columns in determination of trichothecene mycotoxins in foods and feeds. J Assoc Off Anal Chem 69(4):699-703

Roszko M, Rzepkowska M, Szterk A, Szymczyk K, Jędrzejczak R, Bryła M (2012) Application of semi-permeable membrane dialysis/ion trap mass spectrometry technique to determine polybrominated diphenyl ethers and polychlorinated biphenyls in milk fat. Anal Chim Acta 748:9-19

Santini A, Ferracane R, Somma MC, Aragón A, Ritieni A (2009) Multitoxin extraction and detection of trichothecenes in cereals: an improved LC-MS/MS approach. J Sci Food Agric 89(7):1145-1153

SCF (2002) Opinion of the Scientific Committee on Food on Fusarium toxins. Parts 6: Group evaluation of T-2 toxin, HT-2 toxin, nivalenol and deoxynivalenol, adopted on 26 February 2002. Scientific Committee on Food: SCF/CS/CNTM/MYC/27 Final. Available at: http://europa.eu. int/comm/foods/fs/sc/scf/out123 en.pdf. Accessed 21 Apr 2013

Schollenberger M, Müller HM, Rüfle M, Drochner W (2008) Natural occurrence of 16 Fusarium toxins in edible oil marketed in Germany. Food Control 19:475-482

Schothorst RC, Jekel AA (2001) Determination of trichothecenes in wheat by capillary gas chromatography with flame ionisation detection. Food Chem 73(1):111-117

Schwake-Anduschus C, Langenkämper G, Unbehend G, Dietrich R, Märtlbauer E, Muänzing K (2010) Occurrence of Fusarium T-2 and HT-2 toxins in oats from cultivar studies in Germany and degradation of the toxins during grain cleaning treatment and food processing. Food Addit Contam 27(9):1253-1260 
SCOOP (2003) Scoop Task 3.2.10: collection of occurrence data of Fusarium toxins in food and assessment of dietary intake by population of EU member states. http://ec.europa.eu/food/fs/scoop/task/3210. pdf. Accessed 16 Apr 2013

Stecher G, Jarukamjorn K, Zaborski P, Bakrya R, Hucka CW, Bonn GK (2007) Evaluation of extraction methods for the simultaneous analysis of simple and macrocyclic trichothecenes. Talanta 73:251257

Suman M, Catellani D (2008) Ion trap LC-MS/MS as a valid multimethod to determine trichothecenes and zearalenone in the food industry. World Mycotoxin J 1(3):255-262
Valle-Algarra FM, Medina A, Gimeno-Adelantado JV, Llorens A, Jiménez M, Mateo R (2005) Comparative assessment of solid-phase extraction clean-up procedures, GC columns and perfluoroacylation reagents for determination of type $\mathrm{B}$ trichothecenes in wheat by GC-ECD. Talanta 66:194-201

Valle-Algarra FM, Mateo EM, Mateo R, Gimeno-Adelantado JV, Jiménez M (2011) Determination of type A and type B trichothecenes in paprika and chili pepper using LC-triple quadrupole-MS and GC-ECD. Talanta 84:1112-1117

Yazar S, Omurtag GZ (2008) Fumonisins, trichothecenes and zearalenone in cereals. Int J Mol Sci 9:2062-2090 